\title{
Interests Analysis on Compulsory license in the Field of Renewable Energy Technology
}

\author{
Meirong Guo \\ Koguan Law School \\ Shanghai Jiaotong University, Shanghai, China \\ guomeirong@sjtu.edu.cn
}

\begin{abstract}
In this paper, the notion that compulsory licenses are relevant with the extended public interest was discussed. For example, climate change and environmental pollution are related with transnational interest; resource depletion is related with generation's interest. Therefore, the interests in the field of renewable energy technology were analyzed by taking advantage of interest as resource and reflective interest in compulsory licenses. Finally, I argued that the interests in the field of renewable energy technology are not only relevant to the present generation living in China but also to other current peoples and future generations. Climate change and environmental pollution are threats to transnational interests, and resource depletion is closely related to the posterity's interest. Moreover, interest as resource and reflective interest of licensee and consumers will be promoted when implement compulsory license in renewable energy technology.
\end{abstract}

Keywords-compulsory license; public interest; renewable energy technology; interest as resource; reflective resource.

\section{The EXTENDED PuBliC INTEREST}

\section{A. Climate Change and Pollution: Threats to Transnational Interest}

Every country has its own interest. Sometimes it is beyond borders and becomes transnational interest. For example, climate change and pollution are related with national interest and also affect global interest. Greenhouse gas (GHG) emission from country A may have a large impact on other countries, which affects transnational interest. At present the main energy source is non-renewable fossil fuels. As a result, conventional infrastructure and transport systems, which are fitted to combustion engines, remain prominent across the globe. The continual use of fossil fuels at the current rate is believed to increase global warming and cause more severe climate change [1].

Climate change can bring about higher seas. It makes communities more vulnerable to storm surges, which can be 56 meters high. The storm surge from cyclone Nargis traveled 35 kilometers inland, killing 140,000 people and flooding around $14,400 \mathrm{~km}$, an area equal to one-third the size of Switzerland. Climate change is not a new phenomenon. It is now widely recognized that the Earth's atmosphere is undergoing profound changes. All of these changes pose grave threats to humanity, non-human animals and the natural world. We are currently experiencing the climate change that differs from the past and shifts in two crucial respects: it is anthropogenic, and it is happening more rapidly than at any time in the last fifty million years [2].

Moreover, we know that human activities have had a significant impact on the global climate system, and that if current trends continue; these impacts will give rise to potentially disastrous effects on the environmental, social, and economic interests of all countries and will have profound consequences for every aspect of human societies. If we focus solely on human impacts, we can say that anthropogenic climate change will jeopardize the following fundamental interests: (a) because of water-borne diseases, vector-borne diseases, and hear stress, it will harm to human health; (b) because of freak weather events such as storm surges, hurricanes, tornadoes, and violent flooding, it will threaten human life; (c) because of crop failure, flooding of agricultural land, and the loss of land caused by desertification and sealevel rise, it will jeopardize subsistence; (d) because of damage to infrastructure, roads, and buildings, it will influence on the capacity to attain a reasonable standard of living [3]. According to the Intergovernmental Panel on Climate Change (IPCC), "the impacts of climate change will fall disproportionately upon developing countries and poor persons within all countries and thereby exacerbate inequalities in health status and access to adequate food, clean water, and other resources" [4]. Therefore, we can say anthropogenic climate change is an unavoidable and global issue in its causes and effects.

Environmental pollution is a cross-border issue and its possible influence on the health of human populations is great. The most serious pollution occurs in newly developing and underdeveloped countries. In poor countries, more than $80 \%$ polluted water have been used for irrigation with about 70 to $80 \%$ food and living security in industrial urban and semi urban areas [5]. Industry, clustered in urban and semi-urban areas and surrounded by densely populated and low-income localities, continues to pollute the environment with impunity [6]. Over the last three decades, there has been increasing global concern over the public health impacts attributed to environmental pollution [7]; human exposure to pollution is believed to be more intense now than at any other time in human existence [8]. Therefore, pollution and its consequences affect everyone and that helps make it an attractive public issue.

Another factor contributing to the political attractiveness of environmental protection is its strong link to public health. When fossil fuels are burned, they create different types of air 
pollution problems. Besides creating particulate matter, burning fossil fuels creates smog. Smog makes the air look brown and dirty and can make people sick if they spend too much time outside. China is one of the largest coal producers, exporters, and consumers in the world. Pollution problems from both burning and mining coal have created serious environment and public health problems. Pneumoconiosis-a deadly respiratory disease, also known as "black lung," caused by inhaling coal dust-is one of the most serious occupational diseases facing coal miners. According to China's Ministry of Health, of the approximately one million people in China suffering from this disease, 600,000 are miners. The number of miners falling ill from pneumoconiosis increases by approximately 70,000 every year. In 2002, 2,343 Chinese minders died of pneumoconiosis, which is nearly half the number of those who die from coal mine accidents in China.

Anthropogenic climate change and pollution will predictably have given the adverse impact on human wellbeing, it seems reasonable to launch the system of compulsory licensing to reduce carbon emissions. Renewable energy sources play a role in providing energy services in a sustainable manner and, in particular, in mitigating climate change and pollution. Indeed, some argue that climate change and pollution are a long-term health problem or that it is an "emergency" thus justifying the use of compulsory licensing to increase access to green technology [9]. Climate change and pollution are often looked as public health issues, while the use of compulsory licensing has been considerably more common for drugs that treat widespread epidemics like AIDS, there has been a recent shift toward using compulsory licensing for a wider spectrum of public health issues.

Moreover, both the 2003 WTO Decision and the 2006 EU Regulation on many European countries have codified compulsory licensing provisions into patent laws that are compatible with the TRIPS agreement. Compulsory licensing expressly states that no limits exist on the scope of diseases for which compulsory licensing may be granted. Widening the scope of compulsory licensing to include long-term public health issues such as breast cancer could potentially open the door for compulsory licensing of renewable energy technology that can help reduce climate change and pollution, a problem that certainly have impacts on long-term public health.

Moreover, both the 2003 WTO Decision and the 2006 EU Regulation on many European countries have codified compulsory licensing provisions into patent laws that are compatible with the TRIPS agreement. Compulsory licensing expressly states that no limits exist on the scope of diseases for which compulsory licensing may be granted. Widening the scope of compulsory licensing to include long-term public health issues such as breast cancer could potentially open the door for compulsory licensing of renewable energy technology that can help reduce climate change and pollution, a problem that certainly have impacts on long-term public health [10].

For example, German intellectual property law permits the most controversial TRIPS flexibility: compulsory licensing in the interest of public welfare. Nevertheless, German continues as a leader of green technology and apparently has yet to exercise the power of compulsory licensing in the green technology sector [9]. As previously described, whether the problems of climate change or pollution in renewable energy technology field have impact on not only national interests but also transnational interests. It is similar as the case of pharmaceutical industry, patients of AIDS or other diseases relevant with long-term health issues live in a particular society, however its influence is beyond borders, and so what is at stake transnational interest.

\section{B. Resource Depletion and Compulsory Licenses: Future Generations' Interest}

Resource depletion is the exhaustion of raw materials within a region. Use of either of forms of non-renewable resources beyond their rate of replacement is considered to be a major cause of resource depletion. Many problems associated with resource depletion can be understood as arising from the increasing energy intensity of extraction as a resource becomes increasingly depleted. There are many examples of justified concern over depletion and unsustainable use of resources-or, at least, the easily reached and relatively cheap to extract ones [11]. The depletion of nonrenewable resources that modern societies depend upon-such as oil, zinc, iron ore, bauxite (to make aluminum), and the "rare earths" (used in many electronic gadgets including smart phones as well as smart bombs) — is a problem of great importance [12]. Although there is no immediate problem of scarcity for most of these resources, which is no reason to put off making societal changes that acknowledge the reality of the finite limits of nonrenewable resources. However, renewable energy sources will also be very important in helping us to make the best use possible of our oil supplies. For example, the EU has set a target to have $20 \%$ of energy produced from renewable sources by 2020 , meaning that governments will be finding ways to increase the use of technologies such as wind, wave and solar power.

Specific improvements in energy-efficient technology mean that compulsory licenses would have to be granted on a variety of innovation to effectively solve the environmental emergency including resource depletion. Resource depletion problem has temporal continuity. It is not only trouble us at present, or in the very short run, but also will confront remote generations. The long-term aspect in fact is a frequent one. From its very beginning, concern for the environment has reflected a preoccupation with the interests of future generations. Inspired by Joel Feinberg's seminal essay (1974), which suggests this idea with caution, many authors maintain that our descendants have the right to require us to protect their interests. For instance, James Sterba (1981) argues that future people have the right to receive the goods and resources necessary for their basic needs.

Problems of definition confront us at the very start. What do we mean by a "generation"? The Concise Oxford Dictionary offers the following choice. We can either mean a single step in descent within a particular family, or a whole body of persons born about the same time. Besides these, there is the third definition about generation, which is differentiated by defining the intended meanings of past, present, and future generations. Some authors note that, we can mark out the line between present and future generations by continuously shifting as time passes [13]. Past generations mean persons 
who are already dead; the present generation refers to individuals who are now alive; and future generations denote those who are not yet born. There are two forms of legacy: natural and human-made from the resourcist perspective. Natural legacy is including some kinds of nonrenewable and renewable resources, which supports human life. Each generation has an obligation to bequeath these items of the natural legacy to its successors by refraining from exhausting the resources. Typical examples of the human-made heritage that is crucial to a decently safe and healthy life include knowledge of renewable energy technology. Each generation is required to develop these products and to hand them over to its successors.

Article 31 of TRIPS permits compulsory licenses in the "case of national emergency" or for "public non-commercial use”. Issuing compulsory licenses for renewable energy technology is likely to be considered "public non-commercial use" when such technology are applied in public welfare. In pharmaceutical industry, such licenses have typically been employed in the past for pharmaceutical products used to fight epidemics such as AIDS; but the scope of compulsory licensing has recently been widened to include long-term health problems such as heart disease and cancer. In fact, in pharmaceutical industry, for example, the interests of people who are AIDS patients have also temporal attribute. Suppose a pregnant woman who is AIDS patient, if she could not get necessary drugs, the mother and children would die. In a word, it is relevant with the interests between present generation and next generation. Nevertheless, in renewable energy technology sector, resource depletion affects not only next generation but also distant generations. Thus, from the perspective of time span, it is obviously that generations' interests in renewable energy technology sector are wider than pharmaceutical field.

\section{INTEREST AS WELFARE AND INTEREST AS RESOURCE}

\section{A. Objections to Interest as Welfare}

As I described in Chapter 3.3.1, taking interest as a person's welfare is a matter of his success in fulfilling his preferences, goals, or ambitions; therefore, the equality of achieving success in economic development is a conception of interest as welfare. However, fulfilling one's deformed desires also meet his interest as welfare, for instance the phenomenon of sour grapes as adaptive preference formation, which can lead to deformed desires. Since the dawn of internal combustion engine technologies in the 18th century, petroleum and other fossil fuels have remained in continual demand. As a result, conventional infrastructure and transport systems, which are fitted to combustion engines, remain prominent throughout the globe. The continual use of fossil fuels at the current rate is believed to increase global warming and make it more severe [14].

We can suppose that future generations, especially distant people, have been accustomed in bad environment with the process of global warm and energy depletion, because they are always living in the surrounding after they are born. Their interest as welfare does not reduce since they presumably think the world has always been this way. However, in fact, global warming and energy depletion have brought about bad impacts.
Let us consider another example of interest as welfare. The idea of weak sustainability, which allows for some natural resources to decrease as long as sufficient compensation is provided by increases in social capital [15]. This compensation is in the form of sustained human welfare. Weak sustainability means that natural resources may decline as long as social capital is increased. It states that "natural capital" can be substituted by "human capital". Social capital incorporates resources such as infrastructure, labor and knowledge. Natural capital covers the stock of environmental assets such as fossil fuels, biodiversity and other ecosystem services [16].

For example, in order to speed up local economic development in China, the government deforests and constructs more roads. Convenient traffic brings about more economic profits, at the same time, the decreasing of trees cause environmental problems. This case suggests that a substitution of natural for man-made capital may not be reversible in the long-term; the economic development can give us abundant life, which meets us interest as welfare. However, it is not desirable that sacrificing nature is in exchange for economic development. Therefore pursuing interest as welfare is objected such as weak sustainability.

\section{B. Interest as Resource}

From the view of interest as resource, resource also includes renewable resource. Renewable resources such as the movement of water (hydropower, tidal power, and wave power), wind and radiant energy from geothermal heat (used for geothermal power), and solar energy (used for solar power) are practically infinite and cannot be depleted, unlike their nonrenewable counterparts, which are likely to run out if not used sparingly [17]. With the more and more capital being from conventional financial actors to sustainable energy field, renewable energy will become mainstream and can be one of the promising ways of energy production, as non-renewable resources decline. This is also reinforced by climate change concerns, nuclear dangers and accumulating radioactive waste, high oil prices, peak oil and increasing government support for renewable energy. These factors are commercializing renewable energy, enlarging the market and growing demand, and the adoption of new products to replace obsolete technology and the conversion of existing infrastructure to a renewable standard.

Strong sustainability is as a support to interest as resource, which assumes that the economic and environmental capital is complementary, but not interchangeable. It accepts that there are certain functions that the environment performs, which cannot be duplicated by social capital. Unlike weak sustainability, strong sustainability puts the emphasis on ecological scale over economic gains. Environmentalists generally reject the concept of weak sustainability and argue that the environment should not be degraded for future generations. Even those who view the environment as merely an economic asset may argue that each generation should inherit at least a similar natural environment [18]. This implies that natural resource has been borrowed and should be passed on from one generation to the next still intact in its original form. 
Under compulsory licenses, there are three parties. The first is the owner of a patent license, called as patentee or licensor. The second is an individual or company, called as licensee. The third is consumers in general. According to the literature, consumers refer to general citizens, rather than government. In the renewable energy field, the theory of interest as resource argues that economic interest and environmental interest are complementary. Compared with the theory of interest as welfare, natural capital including resources and environmental interest are more emphasized. As far as patentees or licensors are concerned in renewable energy field, their interest will be improved. More and more people pursue not only economic interest but also sustainable development, and they have to consider surrounding environment at the same time. In order to decrease the environmental pollution, comparatively more renewable energy technology will be used.

Thus, the needs of renewable energy technology patent will be increased. For licensees, their interests will be improved undoubtedly. When the needs of renewable energy technology are enlarged, more and more people have interest in making research on renewable energy technology and there will be more new patent invented. Now let us look at the interests of the consumers. With more and more renewable energy technology is taken advantage of, the problems of climate change and environmental pollution will be softened. For consumers, they can enjoy comfortable life such as beautiful weather and clean water and so on. They satisfy their lives than before.

In the field of renewable energy, because compulsory license reduces the short-term economic interests of the patent owner, it is expected that the patent owner does not want this system. Therefore, the introduction of compulsory license system may reduce the interest as welfare of the patent owner. On the other hand, it is expected that the introduction of compulsory license can alleviate problems such as climate change and pollution in the long term. From the view of providing the necessary goods of healthy and safe life, we can say that it increases the stakeholders of interest as resource including the patent owner. As discussed in Chapter 3, the theory of interest as welfare is not considered to be persuasive. The reduce of interest as welfare cannot be an opposite reason to compulsory license. Nevertheless, the increase of interest as resource could be a reason to support compulsory license.

\section{VOLITIONAL INTEREST AND REFLECTIVE INTEREST}

\section{A. Objections to Volitional Interest}

Someone's volitional well-being is improved, and just for that reason, when he has or achieves what in fact he wants. For example, it is one's volitional interest to smoke just because he likes smoking. Smoking is unhealthy. When the price of cigarette is lower, for smoker his volitional interest may be met, however his health may be destroyed. Just as we all know, pursuing plenty of economic interest and having good living are hopes of most of people in the world. Especially, as China is a developing country, it has used too much non-renewable energy in order to develop economy rapidly in a short term. In the past thirty years, China has got a remarkable increase in economy indeed. The total value of China's trade with the rest of the world surged from approximately US \$300 billion in 2001 to US\$1.5 trillion in 2010.

However, with the development of economy, more and more environmental problems need to be faced. For example, to our surprise, the wish that people want to breathe fresh air has become a dream in some cities of China. How to continue developing economy in the future and how to solve these environmental problems brought out by unsustainable development? China has attempted to leverage this tremendous increase in global trade to improve its people's standard of living. At present, the main energy source used by China is non-renewable resource. The continual use of fossil fuels at the current rate is believed to make an impact on surrounding environment.

As a result, from a view of environmental protection, it is a comfortable option to take advantage of renewable energy technology as soon as possible. However, compared with nonrenewable energy, it needs to spend more time on developing renewable energy technology or taking effect in practice. It might affect economic development and violate the volitional interest of living in an affluent society rapidly. However, it is crucial to the interest of generations now and in the future.

\section{B. Reflective Interest}

Reflective interest is relevant with long-term interest. For instance, national health insurance must be joined without joining any other commercial insurance in Japan. For some people, the system of compulsory health insurance may reduce their volitional interest in a short-term, because they must pay insurance fee every month. However, reflective interests may be promoted in the long run. Especially when someone has serious illness, it does soften the economic burden of the patient.

The idea of reflective interest is crucial in compulsory license in renewable energy technology field. Some express, on behalf of developing countries, the concern that compulsory licensing will adversely affect investing from those foreign companies, because their incentives may be weakened. Moreover, the counts of patent filing in developing countries are constantly increasing recently. If developing countries implement compulsory licensing in renewable energy technology field, some people are afraid of having an inclination to decrease the counts of patent filing in these countries. However, compared with the related environmental problems such as climate change, environmental pollution and energy depletion, the above-mentioned items are short-term interest, which is relevant to economic development. Just as stated before, the problems of climate change, environmental pollution and energy depletion are crucial to not only national interest but also transnational interest. Moreover, it is connected with future generations' interest.

As stated as before, there are three parties under compulsory licensing -patentee or licensor, licensee, and consumers. What is the change of their reflective interest when compulsory licensing is implemented in the renewable energy technology field? If one was well informed and made a choice with no fraud, threat, or mental disorder, his reflective interest is advanced and irrespective of whatever is actually desired. To 
be concrete in renewable energy field, developing renewable energy technology can solve those critical environmental problems and promote the consumers' long-term interest. If one clearly knows the benefits which renewable energy technology can bring him, his interest may be seen as his reflective interest.

For patentee or licensor, when compulsory license will be implemented in the renewable energy field, he is well informed and made a choice in a fair surrounding-without fraud, threat, or mental disorder. Here, his reflective interest will be promoted. For licensee, when compulsory licensing will be implemented on renewable energy field, his economic interest is certainly increased. He can take advantage of the technology freely in a low price. When he knows the benefits which compulsory licensing can bring him, his decision brings him reflective interest will also be satisfied. At last, for consumers, they can pay for little money and consume renewable energy technology. Their economic interest will be improved undoubtedly. Only when they make choices on the surrounding of no fraud, threat, or mental disorder, no matter what they are really want; their reflective interest will be up.

\section{CONCLUSIONS}

I argued that interests in the field of renewable energy technology are not only relevant to the present generation living in China but also to other current peoples and future generations. Climate change and environmental pollution are threats to transnational interests; besides, resource depletion is closely related to the posterity's interest. Moreover, interest as resource and reflective interest of licensee and consumers will be promoted, when implement compulsory license in renewable energy technology.

\section{REFERENCES}

[1] National Research Council. 2010. "America's Climate Choices: Panel on Advancing the Science of Climate Change". The National Academies Press.
[2] Posner, E. A., Weisbach, D. 2010. Climate Change and Future Justice. Princeton University Press.

[3] Caney, S. 2011. "Climate Change, Energy Rights, and Equality". Cambridge University Press: 78.

[4] Watson, R. T., the Core Writing Team. 2001. "Intergovernmental Panel on Climate Change, Climate Change 2001: A Synthesis Report". Cambridge University Press: 12.

[5] World Health Organization. 1989. "Guidelines for Safe Use of Wastewater and Excreta in Agriculture and Aquaculture: Measures for Public Health Protection”, 187.

[6] Government of Pakistan. 2009. "Economic Survey of Pakistan, Finance Division, Economic Division Wing”, Islamabad.

[7] Kimani, N. G. 2007. "Environmental Pollution and Impacts on Public Health: Implications of the Dandora Dumping Site Municipal in Nairobi, Kenya”. United Nations Environment Programme: 1-31.

[8] Schell, L. M., Gallo, M. V., Denham, M., and Ravenscroft, J. 2006. "Effects of Pollution on Human Growth and Development: An Introduction”. Journal of Physiological Anthropology, 25(1): 103-112.

[9] Percival, R., Miller, A. 2011. "Resolving Conflicts between Green Technology Transfer and Intellectual Property Law”. Climate Change, 14.

[10] Fair, R. 2010. "Does Climate Change Justify Compulsory Licensing of Green Technology”. Brigham Young University International Law and Management Review.

[11] Vaccari, D. A. 2009. "Phosphorus Famine: A Looming Crisis". Scientific American: 54-59.

[12] Magdoff, F. 2013. "Global Resource Depletion: Is Population a Problem”. Monthly Review, 64.

[13] Usami, M. 2011. "Intergenerational Justice: The Rights of Future People or the Duty of Fair Play,” Discussion Paper, No. 2011-05, Department of Social Engineering, Tokyo Institute of Technology, November 23,2011.

[14] Board on Atmospheric Sciences and Climate. 2010. "Advancing the Science of Climate Change”. The National Academies Press.

[15] Solow, R.M. 1993. "An Almost Practical Step towards Sustainability". Resources Policy, 16: 162-172.

[16] Stern, D.I. 1997. "The Capital Theory Approach to Sustainability: a Critical Appraisal”. Journal of Economic Issues, 31(1): 145-73.

[17] Eisenberg, R., Nocera, D. 2007. "Preface: Overview of the Forum on Solar and Renewable Energy."

[18] Beder, S. 1996. "The Nature of Sustainable Development, 2nd edition”. 